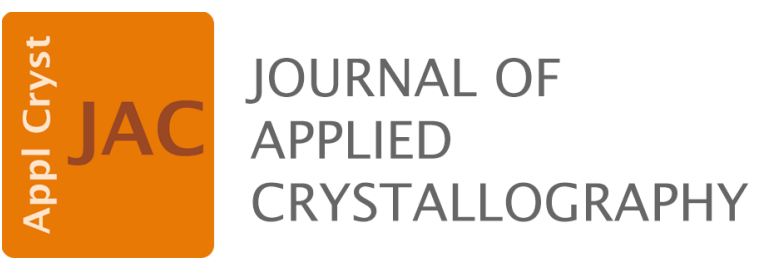

Volume 54 (2021)

Supporting information for article:

Analyses of hierarchical structures in vulcanized SBR rubber by using contrast variation USANS and SANS

Mikihito Takenaka, Shotaro Nishitsuji, Yuki Watanabe, Daisuke Yamaguchi and Satoshi Koizumi 


\section{Data Correction}

According to Choi et al. (Choi et al., 2000), the SANS data $I_{C A L}$ corrected for background of an empty cell, electronic noise of detector, detector sensitivity is given by

$$
I_{C A L}=\left[\left(I_{S A M}-I_{B G D}\right)-\left(\frac{T_{\text {sample }+ \text { cell }}}{T_{\text {cell }}}\right)\left(I_{E M P}-I_{B G D}\right)\right] / \text { Sen }
$$

Here $I_{S A M}, I_{B G D}$, and $I_{E M P}$ are, measured raw data for sample, an empty sell, and electronic noise of detector, respectively. $I_{E M P}$ was measured with beam being blocked. $T_{\text {sample }+ \text { cell }}$ and $T_{\text {cell }}$ are transmission of sample and an empty cell, respectively. We obtained the transmission by measuring the incident beam with the monitor detector (Koizumi et al., 2007). Sen is the normalized detector sensitivity obtained with the measurement of the incoherent scattering of water. In order to estimate the absolute intensity $I_{A B S}$ from $I_{C A L}$, we measured the standard sample Al sample and calibrated by using

$$
I_{A B S}=\left(\frac{I_{C A L}}{I_{S T D}}\right)\left(\frac{d_{S T D}}{d_{\text {sample }}}\right)\left(\frac{T_{S T D+\text { cell }}}{T_{\text {sample }+ \text { cell }}}\right) I_{A B S, S T D}
$$

Here, $I_{S T D}, I_{A B S, S T D}$ are, $I_{C A L}$ for the standard sample and the absolute intensity for the standard sample, respectively. $d_{S T D}$ and $d_{\text {sample }}$ are the thickness of the standard sample and the sample, respectively. $T_{S T D+c e l l}$ is the transmission of the standard sample.

The incoherent scattering $I_{i n c}$ is estimated from the transmission of the samples (Shibayama et al., 2009). $I_{\text {inc }}$ is given by

$$
I_{\text {inc }}=\mu\left(e^{-\mu d_{\text {sample }}}-1\right) /\left(4 \pi \mu d_{\text {sample }}\right),
$$

where $\mu=-e^{T_{\text {sample+cell }}} / d_{\text {sample }}$. 


\section{DSANS Pattern}

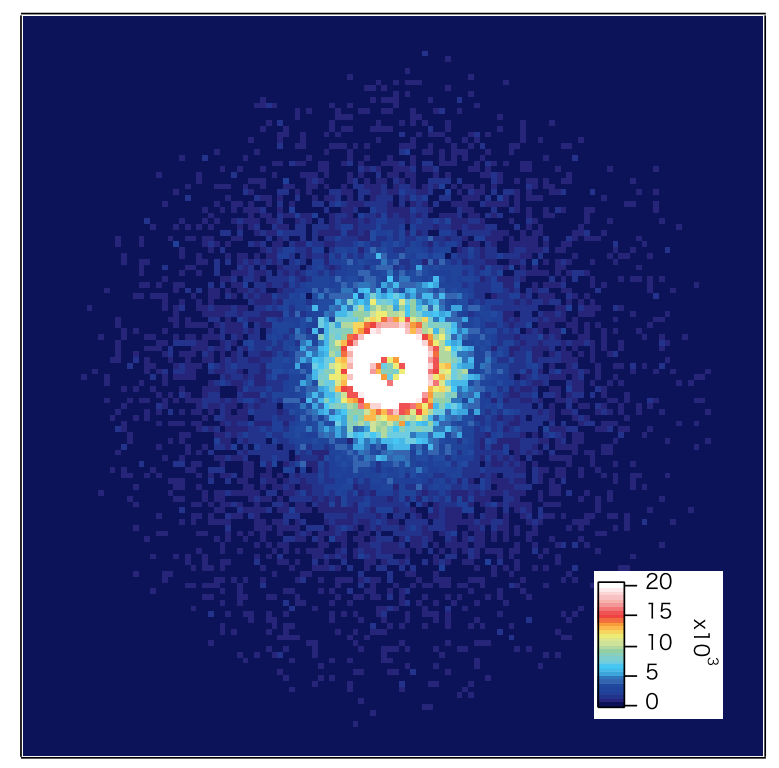

Figure S1 2DSANS pattern of SBR015

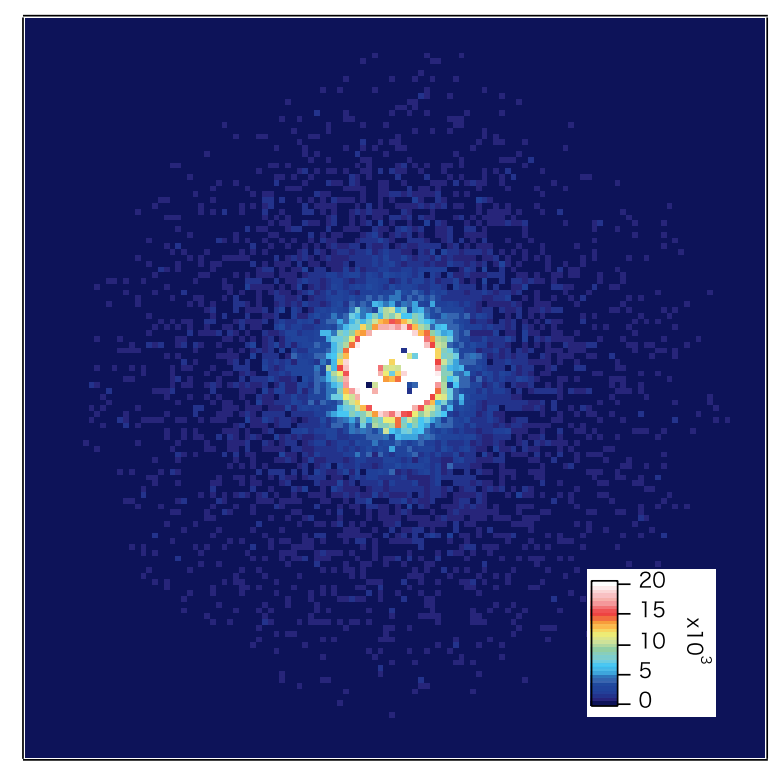

Figure S2 2DSANS pattern of SBR060 


\section{Reference}

Choi, S. M. (2000). SANS Experimental Methods. Presented at the NIST Center for Neutron Research Summer School, Gaithersburg, MD

Koizumi, S.; Iwase, H.; Suzuki, J. I.; Oku, T.; Motokawa, R.; Sasao, H.; Tanaka, H.;

Yamaguchi, D.; Shimizu, H. M.; Hashimoto, T. (2007). J. Appl. Cryst. 40, s474-s479.

Shibayama, M.; Matsunaga, T.; Nagao, M. (2009). J Appl Crystallogr 42, 621-628. 